\title{
Pattern and Trend of Mortality among Males in Egypt from 2000 to 2015
}

\author{
Sally Sonia Simmons ${ }^{1 *}$ Marlen Bruentrup ${ }^{2}$ \\ ${ }^{1}$ Institute of Demography, National Research University-Higher School of Economics, \\ Myasnitskaya, 20, 101000, Moscow, Russia \\ ${ }^{2}$ Institute for Statistical Studies and Economics of Knowledge, National Research University \\ Higher School of Economics, Myasnitskaya, 20, 101000, Moscow, Russia.
}

Corresponding Author Sally Sonia Simmons

Mobile:

$+79779716963$

E mail:

ssimmons@edu.hse.ru

Key words: Pattern, Trend, Mortality, Males, Egypt
Background and study aim: Circulatory and respiratory diseases, neoplasms and external causes of death are the major clusters of diseases leading causes of death among males in Egypt. We studied the age- and cause-specific mortality among males in Egypt from 2000 to 2015. The study measured the trends in age- and cause-specific mortality and the recorded rates of the standardized deaths among males in Egypt.

Materials and Methods: We used data from the World Health Organization Mortality Database and United Nations Population Division to estimate the standardized death rates from circulatory and respiratory diseases, neoplasms, external causes and all other causes of death among males in Egypt for a period of 16 years.

Results: We found that recorded death rates from circulatory diseases were highest while death rates from external causes were the least. All the causes of death we studied were highest in ages 45 and above years. Youthful ages recorded the least mortality from all the cause of mortality we studied.

Conclusion: Health policies and programs should target circulatory diseases and its related mortality and the other causes of death in the adult and elderly years of male life in Egypt.

\section{INTRODUCTION}

Circulatory (CVD) and respiratory diseases and neoplasms are the most recurring clusters of non-communicable diseases in Egypt. Mortality from these diseases is overly burdensome in the country. Aside from these, deaths from external causes have been documented to increase annually [1,2]. In 2014, 85\% of deaths in the country were caused by these non-communicable diseases [3]. Considering the major classes of death identified above, CVDs are the ultimate cause of death in Egypt. Approximately, 21\% of all mortality cases in the country is attributed to morbidity from CVD diseases such as ischaemic heart disease. In recent times, the incidence and mortality from CVD have been found to have risen in Egypt [4]. Mortality from respiratory diseases in Egypt declined substantially between 2005 and 2015 [5]. Agestandardized neoplasms incidence rates were about 166.6 per 100000 Egyptians [6]. External causes rank fifth among all causes of death in Egypt [1].

CVD, respiratory diseases and neoplasms are regarded as the primary causes of mortality among adults in Egypt [7]. More so, these causes of death are in particular common among males in Egypt [1,8]. Again, in the youthful ages, from 15 to 24 years, mortality from CVD, respiratory diseases and neoplasms are less prevalent in Egypt. Fouad et al. [9] attributed the divergence to tobacco smoking in the adult years than in the youthful ages. Further, the authors documented an increase in tobacco smoking and hypertension since 2010. The conventional risk factors associated with the incidence of diseases and mortality are categorised as behavioural, clinical and demographic factors. The 
behavioural risk factors include unhealthy diet, inadequate physical inactivity, tobacco use and perilous use of alcohol [7,9-11]. The clinical factors manifest as limited health care infrastructure, inadequate health care facilities and lack of trained medical professionals to assist clients with the management of the diseases. Aging is a demographic factor the influences the onset of these causes of death $[7,12]$. Genetics also plays an essential role in the occurrence of these diseases and their related deaths in the early years of the life of a person [13].

Mortality from non-communicable diseases is higher among males than females in Egypt $[6,14]$. Also, the trend in causes of death among Egyptian males increased from 2000 to 2013 by about 51 to $54 \%$ [15]. $82.7 \%$ of all cases of accidents are recorded among males in Egypt. Moreover, males are twice as females at risk of mortality from external causes in the country. In the adolescent and youthful ages, the vulnerability of Egyptian males to external causes of mortality is heightened [16]. Consequently, single causes of death such as ischaemic heart diseases, diabetes, hypertension, road and traffic accidents, and chronic obstructive pulmonary disease but not the major clusters of causes of death among Egyptian males have been studied. Besides, most studies focus on both sexes instead of a single sex. That said, the trend in male mortality from CVD, respiratory diseases, neoplasm and external causes in Egypt have not been the focus of researchers. This lessens the details derived from the studies as the explanation of causal mechanisms as well as course of events are general than specific [17]. Thus, a detailed understanding of the sequence of pattern and trend in male mortality from these broad cause of mortality in Egypt is needed. The study, therefore, analysed the pattern and trend in male mortality from CVD, respiratory diseases, neoplasm and external causes in Egypt from 2000 to 2015 . This study will assist policy makers in policy targeting when dealing with health promotion as well as disease prevention and control.

\section{MATERIALS AND METHODS}

\section{Study Design}

We employed a retrospective explorative time series design. The design assisted with the description and analysis of records of mortality among males over the period under study. Further, such study designs enhances the formation of practical administrative decisions. For the reason that the design serves as of hypotheses for decisions [18].

\section{Data Availability}

In our study, we used data from the World Health Organisation (WHO) Mortality Database and United Nations Population Division. The data used from the two repositories included the number of deaths by year, age group, sex, causes of death and the population size of Egypt. Information on the males, age variations and mortality from neoplasms, diseases of the circulatory system and diseases of the respiratory system, external causes morbidity and mortality and other causes from 2000 to 2015 as defined by the International Statistical Classification of Diseases and Related Health Problems 10th revision (ICD 10) were used for the study $[\mathbf{1 9 , 2 0 ]}$. These groups of diseases were represented with the ICD codes; C00-D48 (neoplasms), I00-I99 (diseases of the circulatory system), J00-J98 (diseases of the respiratory system), V01-Y98 (external causes morbidity and mortality) and TOT (All Causes). Based on all causes (TOT), we defined all the other causes of death as the causes of death which exclude neoplasms, respiratory diseases, CVD and external causes [19].

\section{Statistical Analyses}

We estimated the age standardized mortality rate using the indirect standardization approach to enhance the description of trends in the major causes of mortality among males. For each period, the recorded number of deaths were for fiveyear age intervals except for age 75 and above. It was found that the ages above 74 years, on the one hand, were categorised as 75 and more years at certain periods and on the other hand, were extended to ages 95 and above years. Hence, the number of deaths at age 75 and above years were aggregated as age 75 and above for all causes of death categories and periods. This was done to help provide a useful and meaningful analysis. Also, for ages $0,1,2,3$ and 4 there were inconsistencies in the records. To alleviate these inconsistencies, we grouped the ages as 0 to 4 years. That said, all the ages were five-year aggregated ages groups ranging from 0 to 75 and more years. The number of deaths recorded by the unknown ages was not available in the data. Thus, the authors did not redistribute those rates to generate an equal number of deaths per case as according to the total number of deaths for each cause of death we studied. It was from these 
outputs that we estimated age and cause-specific death rates (圆 $M_{x}$ ) among males from 2000 to 2015. The age-specific mortality rate for the CVD, respiratory diseases, neoplasms and external causes among males were standardized using the WHO standard population (回 $C_{x}$ ) [21]. The age standardized death rates formula for the study was:

$$
\sum_{x=i}^{\infty} \text { 目 } M_{x} * \text { 圆 } C_{x}
$$

This approach allowed the elimination of the effect of age composition on the causes of death among the male population of Egypt [22,23]. Again, it allowed for a critical, meaningful and detailed analysis of differences in the causespecific age-standardized death rates among the Egyptian males [24]. Our analyses were undertaken in R Studio version1.1.456.

\section{RESULTS}

\section{Trend Analysis}

Figure 1 shows the trends in the age-standardized death rates from neoplasms, circulatory disease, respiratory diseases, external causes and other causes of death in males in Egypt, from 2000 to 2015. In 2000, all other causes of death exceeded CVD, respiratory, neoplasms and external causes. However, from 2001 to 2015 CVD became the leading cause of death of males in Egypt. It was about four times the deaths from respiratory, neoplasms and external causes of death. Conversely, from 2000 to 2015, external causes of death were fairly stable and the least recorded cause of death among the five major classes of causes of death under study. From 2011 to 2013, deaths from all causes increased with the exception of mortality from external causes. However, all but external causes of death decreased in 2014. Whereas CVD spiked in 2013, respiratory diseases declined from 2005 to 2010, rose in 2011 and plateaued from 2012 to 2013. Moreover, in 2015, mortality from CVD and respiratory diseases increased among Egyptian males.

\section{Age Pattern Analysis}

Figure 2 shows the contribution of each group to the age-standardized death rates from neoplasms, circulatory disease, respiratory diseases, external causes and other causes of death in males in Egypt from 2000 to 2015 . Generally, age groups 45 and above years recorded more deaths from circulatory (CVD), respiratory diseases and neoplasms whereas ages 5 to 24 years recorded the least. The recorded death rates from these diseases were highest in 2012 and 2013. In the initial years, other causes of mortality were the highest cause of death among males aged 45 and above years in Egypt. However, within time circulatory diseases became the highest while external causes remained the lowest. Mortality from respiratory diseases and neoplasms increased among the males aged 45 and above years. Males who were in the age group 0 to 4 years recorded higher death rates from CVD, respiratory and other causes than those aged 5 to 44 years. Over time, the recorded death rates from these diseases among males aged 0-4 years reduced. Until 2012, mortality from all the causes of death we studied was minimal among males who were 5 to 24 years of age. 


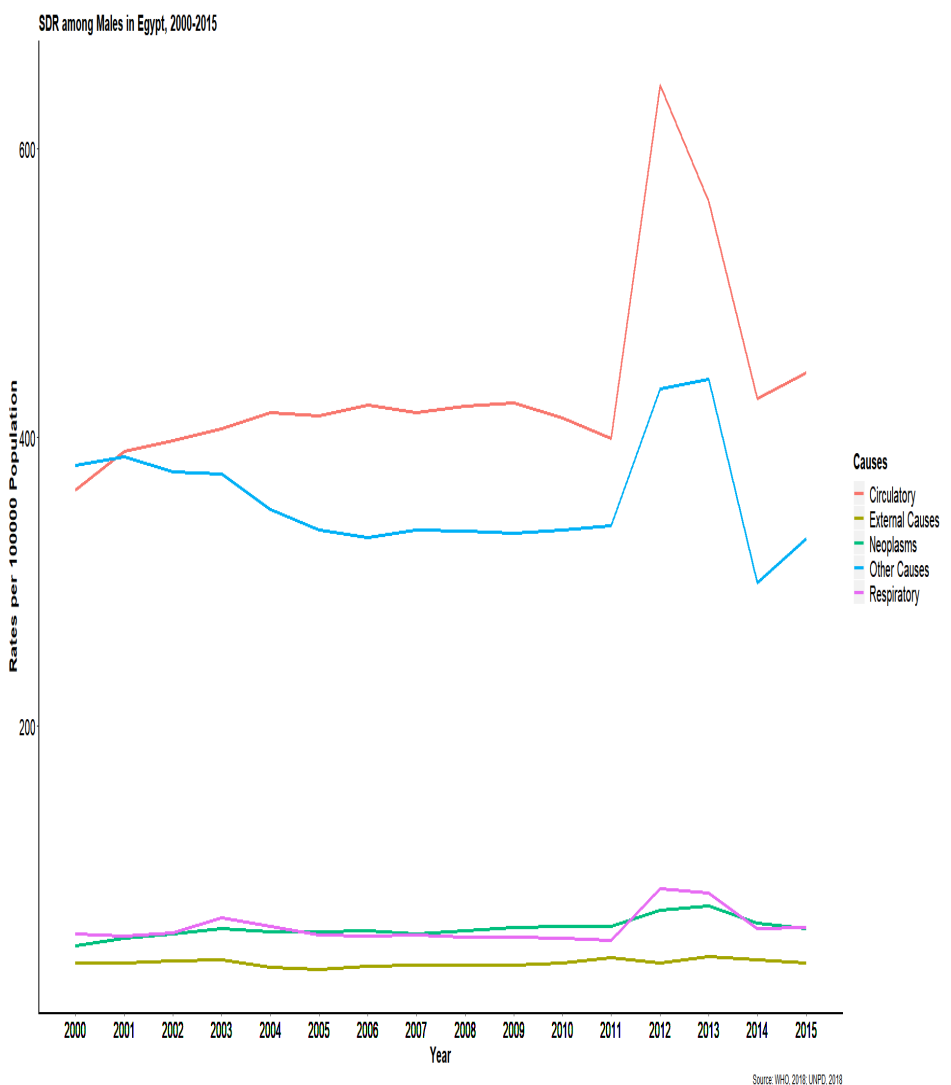

Figure (1): standardized death rates (SDR) from neoplasms, circulatory disease, respiratory diseases, external causes and other causes of death in males (Egypt, 2000-2015)

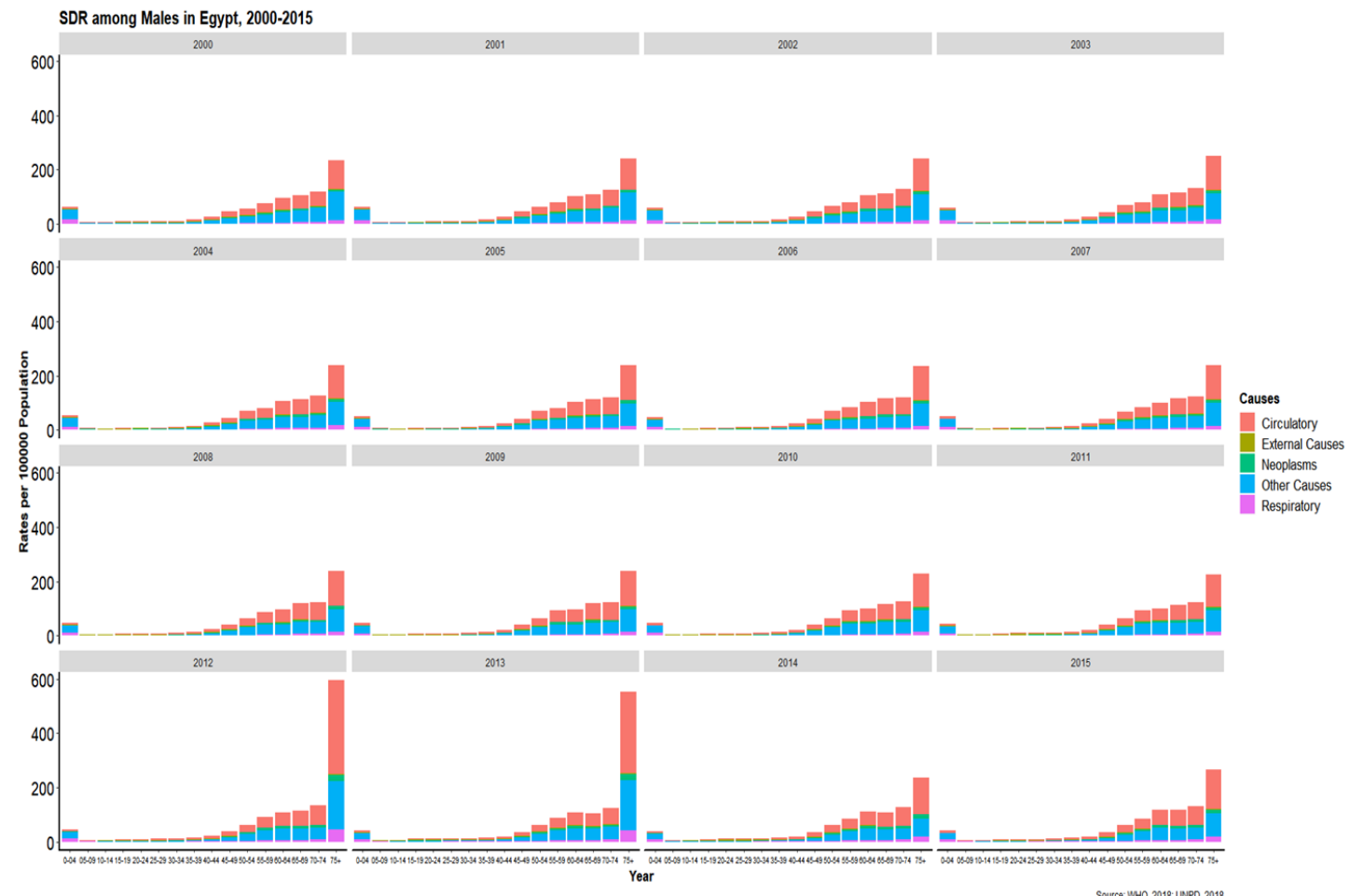

Figure (2) : Age standardized death rates of major classes of causes of death to life expectancy by (Egypt, 2000-2015)

Simmons and Bruentrup , Afro-Egypt J Infect Endem Dis 2019; 9(1):74-80

https://aeji.journals.ekb.eg/

http://mis.zu.edu.eg/ajied/home.aspx 


\section{DISCUSSION}

This is the maiden study to analyse the age- and cause-specific mortality of major classes of causes of death among males in Egypt from 2000 to 2015. Using data from WHO Mortality Database and United Nations Population Division for Egypt, we, on the one hand, studied the trends in standardized mortality rates from CVD, external causes, neoplasms and respiratory diseases for males and on the other hand, examined the occurrences of these causes of death in the age groups of the Egyptian males. CVD was endemic among these males over the period we studied. The number of deaths reported to be caused by CVD was about four times higher than deaths from respiratory, neoplasms and external causes of death. This finding affirms See, Jeppsson, Stafström [4] postulation that CVD is the leading cause of mortality in Egypt. Yet, neoplasms and respiratory diseases related deaths were also recurrent among these males although mortality from respiratory diseases declined than neoplasms. Our finding corroborates the assertion that mortality from respiratory diseases in Egypt has declined [5]. However, we found a contrary result to the trend in decline as specified by Morgan in 2017. In that respiratory diseases decline to about 2010, rose in 2011 plateaued in 2012 and 2013 and decline in 2014.

Our study revealed that mortality from CVD, respiratory diseases, neoplasms, and external causes were higher in the adult and elderly years, age 45 and above than in the youthful ages. This finding confirms the theory that CVD and respiratory diseases and neoplasms primary causes of mortality among adults than the youth in Egypt [7,8]. Besides, it affirms Fouad, Awa, Naga, Emam, Labib, Palipudi [9] finding that CVD, respiratory diseases and neoplasms were not common in the youthful ages of males in Egypt because of the decreased incidence of smokers in that age group. Also, the inadequate physical activities observed in the older ages among males in Egypt accounts for the higher rates deaths recorded from CVD, respiratory diseases and neoplasms in the elderly years of male life in Egypt $[\mathbf{1 2 , 2 5}]$. Our finding that these diseases under study are relative higher in the under-five years of male children in Egypt corroborate the fact that during the under five years of life, poor dietary habits perturb the body's homeostasis and thereby creates a loop for CVD, respiratory diseases and neoplasms to manifest [26] and the research that under-five children can inherit the gene from a parent [13]. External causes were the least recorded causes of death among males. The position of external causes in our study is similar to Mahran and colleagues [1] declaration that external causes rank fifth among all causes of death in Egypt.

\section{CONCLUSION}

The major finding of our study is the quadruple difference in the increase in mortality from CVD as compared to respiratory diseases, neoplasms and external causes among males in Egypt from the years 2000 to 2015 . This outcome is higher than expected. Therefore, health prevention and promotion programs should focus on CVD and the most at risk population, persons aged 45 and above years. Further research is need to quantify the gender differences in the death rates from these major classes of causes of death. These studies will be necessary for understanding of the phenomenon and covering the limitations of our methods.

\section{Authors Contribution}

SSS conceived the study and performed the analysis. SSS and MB drafted and edited the manuscript. The authors proof-read the final manuscript and approved it.

Funding: There was no funding for our study.

\section{Conflicts of Interest}

The authors declare that there is no conflict of interests.

\section{Ethical Consideration}

Our study sort no ethical approval from the author's institution since the manuscript used anonymous secondary data.

\section{Acknowledgments}

The authors acknowledge WHO and UNPD, World Bank for providing with the data upon which the findings of this study were based. The authors are grateful to Vladimir Alexander Kozlov and Bernard Baffour for their valuable contributions and comments while drafting the manuscript.

\section{REFERENCES}

1- Mahran D, Farouk O, Qayed M, Berraud A. Hospitalized injuries and deaths in a trauma unit in upper Egypt. International Journal of Critical Illness and Injury Science 2013; 3; 235. 
2- Mahran D, Farouk O, Qayed M, Berraud A. Pattern and Trend of Injuries Among Trauma Unit Attendants in Upper Egypt. Trauma Monthly 2016; 21.

3- Allen LN, Pullar J, Wickramasinghe KK, Williams J, Roberts N, Mikkelsen B, et al. Evaluation of research on interventions aligned to WHO 'Best Buys' for NCDs in low-income and lower-middle-income countries: a systematic review from 1990 to 2015. BMJ Global Health 2018; 3; e000535.

4 - See S, Jeppsson A, Stafström M. What is killing? People's knowledge about coronary heart disease, attitude towards prevention and main risk reduction barriers in Ismailia, Egypt (Descriptive crosssectional study). Pan African Medical Journal $2013 ; 15$.

5- Morgan J. Egypt's respiratory health in focus. The Lancet Respiratory Medicine 2017; 5; 929930.

6- Ibrahim AS, Khaled HM, Mikhail NN, Baraka H, Kamel H. Cancer Incidence in Egypt: Results of the National Population-Based Cancer Registry Program. Journal of Cancer Epidemiology 2014; 2014; 1-18.

7- Lomas DA. Does Protease-Antiprotease Imbalance Explain Chronic Obstructive Pulmonary Disease? $2016 ; 13 ; 8$.

8- Mandil A, Chaaya M, Saab D. Health status, epidemiological profile and prospects: Eastern Mediterranean region. International Journal of Epidemiology 2013; 42; 616-626.

9- Fouad H, Awa FE, Naga RAE, Emam A H, Labib S, Palipudi KM, et al. Prevalence of tobacco use among adults in Egypt, 2009. Global Health Promotion 2016; 23; 38-47.

10- Karim OA, Ammar A, Chtourou H, Wagner M, Schlenker L, Parish A, et al. A Comparative Study of Physical Fitness among Egyptian and German Children Aged Between 6 and 10 Years. Advances in Physical Education 2015; 05; 7-17.

11- Thun M, Peto R, Boreham J, Lopez AD. Stages of the cigarette epidemic on entering its second century. Tobacco Control 2012; 21; 96-101.

12- Mashahit M, Hussein H, Hanafy E. Screening for Non-communicable Diseases in Public Places in Upper Egypt. Asian Journal of Medicine and Health 2017; 8; 1-6.

13- Toss A, Tomasello C, Razzaboni E, Contu G, Grandi G, Cagnacci A, et al. Hereditary Ovarian Cancer: Not Only BRCA 1 and 2 Genes. BioMed Research International 2015; 2015; 1-11.

14- Hegazi R, El-Gamal M, Abdel-Hady N, Hamdy O. Epidemiology of and Risk Factors for Type 2
Diabetes in Egypt. Annals of Global Health $2016 ; 81 ; 814$.

15- Trend of Ill-Defined Causes of Death in Egypt (2000-2013) in Comparison to Selected Eastern Mediterranean Countries, and an Intervention Study to Improve The Accuracy of Death Certification in One District in Cairo, Egypt. The Egyptian Journal of Community Medicine 2017; 35; 35-48.

16- Afifi RM, Zaytou SS, El Raggal AA, Qulali A, Ayoub HAK. Involvement of Male Youth into Accidents in Upper Egypt: Pattern and Risk Analysis. Health 2015; 07; 965-975.

17- Bloemraad I. The promise and pitfalls of comparative research design in the study of migration. Migration Studies 2013; 1; 27-46.

18- Gottman JM, McFall RM, Barnett JT. Design and analysis of research using time series. Psychological Bulletin 1969; 72; 299-306.

19- Bots SH, Peters SAE, Woodward M. Sex differences in coronary heart disease and stroke mortality: a global assessment of the effect of ageing between 1980 and 2010. BMJ Global Health 2017; 2; e000298.

20- Martins RC, Buchalla CM. Codificação e seleção automáticas das causas de morte: adaptação para o uso no Brasil do software Iris. Revista Brasileira de Epidemiologia 2015; 18; 883-893.

21- Rosella LC, Calzavara A, Frank JW, Fitzpatrick T, Donnelly PD, Henry D. Narrowing mortality gap between men and women over two decades: a registry-based study in Ontario, Canada. BMJ Open 2016; 6; e012564.

22- Li C, Ford ES, Zhao G, Wen X, Gotway CA. Age adjustment of diabetes prevalence: Use of 2010 US Census data 根据年龄调整的糖尿病患病率：使用美国201 0 年人口普查数据: Age adjustment using 2010 US Census data. Journal of Diabetes 2014; 6; 451-461.

23- Preston SH, Stokes A. Sources of Population Aging in More and Less Developed Countries. Population and Development Review 2012; 38; 221-236.

24- Shkolnikov VM, Andreev EM, McKee M, Leon DA. Components and possible determinants of decrease in Russian mortality in 2004-2010. Demographic Research 2013; 28; 917-950.

25- Khadr Z, Yount K. Differences in Self-Reported Physical Limitation Among Older Women and Men in Ismailia, Egypt. The Journals of Gerontology Series B: Psychological Sciences and Social Sciences 2012; 67; 605-617. 
26- Nutrition Department, Faculty of Allied Medical Sciences, Pharos University, Alexandria, Egypt., Salama AA. Overweight and Obesity among Preschool Children aged 2-5 Years in Alexandria, Egypt. Canadian Journal of Clinical Nutrition January 2018; 34-54.
27- United Nation Population Division, 2018. https:// population.un.org/wpp/Download/Standard/Popu lation/

28- World Health Organisation, 2018. http://apps. who.int/healthinfo/statistics/mortality/causeofdea th_query/ 